\section{Case Reports in Nephrology and Dialysis}

Case Rep Nephrol Dial 2021;11:103-109

DOI: $10.1159 / 000515062$

Published online: April 21, 2021

(C) 2021 The Author(s)

Published by S. Karger AG, Basel www.karger.com/cnd

This article is licensed under the Creative Commons Attribution-NonCommercial 4.0 International License (CC BY-NC) (http://www.karger.com/Services/OpenAccessLicense). Usage and distribution for commercial purposes requires written permission.

\title{
A Case of Nephrotic Syndrome that Resolved with Influenza B Infection
}

\author{
Hiroshi Tamura Shohei Kuraoka Yuko Hidaka Hiroko Nagata \\ Keishiro Furuie Hitoshi Nakazato
}

Department of Pediatrics, Faculty of Life Sciences, Kumamoto University,

Kumamoto, Japan

\section{Keywords}

Nephrotic syndrome $\cdot$ Spontaneous remission · Influenza B infection · Children

\begin{abstract}
It has been postulated that measles virus infection is associated with remission of idiopathic nephrotic syndrome (INS) in childhood. There are few reports on the correlation of INS remission with other infections. Previously, there have been two case reports suggesting an association between influenza B virus infection and the remission of INS. The patient was an 18-yearold Japanese woman. The onset of steroid-sensitive NS was at 9 years of age, and pathological diagnosis was minimal change nephrotic syndrome (MCNS). Until 10 months prior to visiting our hospital, the patient's NS was in remission. The patient experienced fever, cough, and malaise and she was diagnosed with type B influenza by a local physician 4 days before visiting our hospital. The patient had vomiting and diarrhea 1 day prior to visiting our hospital. Her weight was $54.7 \mathrm{~kg}(+5.0 \mathrm{~kg})$ and she had pitting edema of both lower legs. Her serum albumin level was $0.9 \mathrm{~g} / \mathrm{dL}$, proteinuria level was $8.73 \mathrm{~g} / \mathrm{gCr}$, and urine sediments showed $1-4$ red blood cells per high-power field. She was diagnosed with relapse of NS. The level of proteinuria decreased to $0.03 \mathrm{~g} / \mathrm{gCr}$ with rest alone on day 4 of admission, and a complete remission from NS was observed at approximately 2 weeks after the onset of influenza B infection. We report a rare case wherein spontaneous remission of NS occurred within a short period of 2 weeks
\end{abstract}

Hiroshi Tamura
Department of Pediatrics
Faculty of Life Sciences, Kumamoto University
$1-1-1$ Honjo, Kumamoto 860-8556 (Japan)
bohm1905HT@kuh.kumamoto-u.ac.jp




\section{Case Reports in Nephrology and Dialysis}

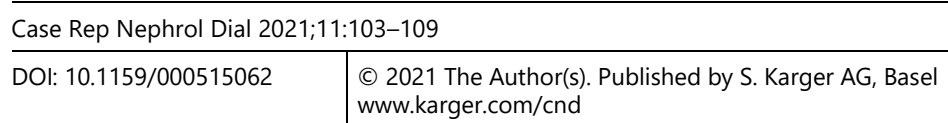

Tamura et al.: A Case of Nephrotic Syndrome that Resolved with Influenza B Infection

after influenza B infection. It is clear that some immunity is involved in the pathogenesis of INS, but there are some cases in which infection improves NS and others in which it recurs.

(C) 2021 The Author(s)

Published by S. Karger AG, Basel

\section{Introduction}

Idiopathic nephrotic syndrome (INS) has been considered to be a T cell disorder. The occurrence of INS remission following measles infection which suppresses T cells, an association with Hodgkin lymphoma, and a response to treatment with agents that inhibit $\mathrm{T}$ cell function [1] provides evidence for this hypothesis.

Previous studies have suggested that measles virus infection is associated with remission of INS in childhood [1,2]. There are few reports on the association of INS remission with other infections. There have been two case reports suggesting an association between influenza B virus infection and the remission of INS $[3,4]$. We report a case of minimal change nephrotic syndrome (MCNS) who had spontaneous remission after contracting type B influenza without steroid administration.

\section{Case Presentation}

The patient was an 18-year-old Japanese woman with a chief complaint of abdominal pain. The onset of steroid-sensitive NS was at 9 years of age, and renal biopsy was performed at 11 years of age. Pathological diagnosis was MCNS. NS was in complete remission with steroid therapy. Frequent relapses occurred, and cyclosporine (CsA) and mizoribine (MZR) were added, but the frequency of relapses did not reduce. Cyclophosphamide was administered at 13 years of age, but the leukocyte count decreased and the treatment was discontinued in 1 month. After that, NS did not relapse, and MZR and CsA were discontinued at 16 and 17 years of age, respectively. The patient has not visited our hospital for 10 months and had no immunosuppressants at the time described below.

The patient experienced fever, cough, and malaise for 5 days prior to visiting our hospital. She was diagnosed with type B influenza and took oseltamivir by a local physician 4 days prior to visiting our hospital. The fever subsided 2 days after consulting the local physician. The patient had vomiting and diarrhea 1 day prior to visiting our hospital. She had severe abdominal pain and came to our hospital by an ambulance.

The physical findings on admission were as follows: height, $155 \mathrm{~cm}$; weight, $54.7 \mathrm{~kg}(+5.0$ $\mathrm{kg}$ ); body temperature, $36.2^{\circ} \mathrm{C}$; blood pressure, $97 / 59 \mathrm{~mm} \mathrm{Hg}$; heart rate, $96 \mathrm{bpm}$; and oxygen saturation on room-air, 99\%. In addition, the patient did not have facial edema but had pitting edema of both lower legs. The laboratory findings were as follows: total protein, $3.4 \mathrm{~g} / \mathrm{dL}$; albumin, $0.9 \mathrm{~g} / \mathrm{dL}$; blood urea nitrogen, $17.7 \mathrm{mg} / \mathrm{dL}$; creatinine, $0.44 \mathrm{mg} / \mathrm{dL}$; estimated glomerular filtration rate, $135.6 \mathrm{~mL} / \mathrm{min} / 1.73 \mathrm{~m}^{2}$; total cholesterol, $255 \mathrm{mg} / \mathrm{dL} ;$ immunoglobulin G (IgG), $210 \mathrm{mg} / \mathrm{dL}$. Her urine protein to creatinine ratio was $8.73 \mathrm{~g} / \mathrm{gCr}$, and urine sediments 


\section{Case Reports in Nephrology and Dialysis}

Case Rep Nephrol Dial 2021;11:103-109

DOI: $10.1159 / 000515062$

(c) 2021 The Author(s). Published by S. Karger AG, Basel www.karger.com/cnd

Tamura et al.: A Case of Nephrotic Syndrome that Resolved with Influenza B Infection

showed 1-4 red blood cells per high-power field without any abnormal casts. There were no notable abnormalities seen in abdominal computed tomography or chest X-ray images. The patient was diagnosed with relapse of NS. But it was not known whether the abdominal pain, vomiting, and diarrhea were due to NS or the gastrointestinal symptoms from influenza B infection, it was decided to inject albumin without prednisolone (PSL) treatment. The level of proteinuria was $8.51 \mathrm{~g} / \mathrm{gCr}$ on day 2 of admission and $0.51 \mathrm{~g} / \mathrm{gCr}$ on day 3. Proteinuria decreased to $0.03 \mathrm{~g} / \mathrm{gCr}$ with rest alone on day 4 . A complete remission from NS was observed at approximately 2 weeks after the onset of influenza B infection.

\section{Discussion/Conclusion}

A case of NS that resolved with influenza B infection was investigated in the literature (Table 1). There were three case reports, including this case, which were examined.

In this case, the patient developed NS before influenza B infection and MCNS was in remission after influenza B infection.

With careful observation in our hospital, complete remission occurred within 9 days after the onset of symptoms without corticosteroid treatment. Although we lacked data on the proteinuria on the day of the influenza B infection diagnosis because no urinalysis was performed at the local clinic where her influenza B infection was diagnosed, we considered the influenza $B$ virus infection to be associated with a remission rather than an exacerbation.

Haruki et al. [4] reported that the patient developed MCNS as a result of changes in immunity due to influenza B infection, and remission occurred because of normalization of the immune system after recovery from this infection.

Kimata et al. [3] reported that they consider influenza B virus infection to have been associated with a remission rather than an exacerbation for the following reason: there is a significant negative correlation between serum albumin levels and the number of days since the appearance of large amounts of proteinuria. From this, the serum albumin concentration at the time of referral in the present case can be ascertained to indicate that the onset of NS occurred prior to admission, which is before the influenza B virus infection [3].

Though the idea that relapse or onset due to influenza infection is different between cases 1 and 2, the clinical course of these three cases is similar (Table 1, Fig. 1). All cases lacked data on the proteinuria on the day of the influenza B infection diagnosis. According to the report [5], the number of days of relapse when suffering from influenza is 1-3 days later. Considering the value of albumin which was seen 5 days after fever in all three cases, nephrotic disease was observed before suffering from influenza. Looking at the report of the spontaneous remission of MCNS [6], it took 25-40 days from the onset of edema to the onset of spontaneous remission, which is different from the three cases this time. We consider that the patients had developed NS before and spontaneously remitted after influenza B infection.

Regarding the relapse of NS, it has long been considered that virus infection was involved. A case had been reported in which a patient with NS had measles and remission of nephrotic disease [2]. It has been reported that CD25+CD4+Foxp3+ regulatory T cells (Tregs) increase in the blood during measles and that changes in the $\mathrm{T}$ cell-producing cytokine balance during

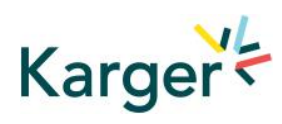




\section{Case Reports in Nephrology and Dialysis}

Case Rep Nephrol Dial 2021;11:103-109

DOI: $10.1159 / 000515062$

(c) 2021 The Author(s). Published by S. Karger AG, Basel www.karger.com/cnd

Tamura et al.: A Case of Nephrotic Syndrome that Resolved with Influenza B Infection

measles are involved in the remission of NS [7]. An increase in the number of Tregs was observed in case 2 in response to intercurrent influenza B virus infection and prednisolone administration, along with a parallel decrease in the amount of proteinuria [3]. Moreover, both influenza virus infection and glucocorticoid administration, which is the key treatment for INS, increase the number of Tregs [8, 9]. Therefore, it may be hypothesized that Tregs play an important role in INS pathogenesis in patients with INS complicated by influenza B infection.

On the other hand, cases of NS relapse due to influenza vaccine and various live vaccines and cases of death due to measles have been reported [10]. Hence, NS may relapse due to influenza infection, and the relationship between NS and Tregs may not be such a simple one. Further investigation is needed.

Regarding the etiology of INS, the "lymphocyte dysfunction theory" proposed by Shalhoub in 1974 has long been believed [1].

That is, in patients with INS, (1) steroids show a rapid and remarkable effect; (2) patients with INS may be in remission when suffering from measles; (3) patients with malignant lymphoma often have INS; (4) in INS patients, lymphocytes release vascular hyperpermeability factors into the culture supernatant; and (5) recurrence of INS patients is significantly higher during upper respiratory tract inflammation.

The lymphocytes mainly comprising T cells of INS patients have dysfunction and overproduce some vascular hyperpermeability factors and cause a large amount of proteinuria $[11,12]$.

In fact, INS patients who had only apheresis (plasma removal) can have remission without steroids or immunosuppressive drugs [13], and newborns born to INS pregnant women have high proteinuria immediately after birth, but disappear spontaneously 3 weeks after birth [14]. There is no doubt that some vascular hyperpermeability factor is involved in the appearance of proteinuria in INS. However, no etiological molecule identified in INS as a factor for increasing the permeability of renal glomerular capillaries with reproducibility and clinical consistency has yet been found.

On the other hand, it is a well-known fact that pediatric INS develops and relapses due to viral infections, such as influenza and insect stings, and immunological stimulation can trigger pediatric INS. In addition, since the onset is sometimes observed in the family, there is high incidence of INS in East Asian children [15] and there is the association of steroid-sensitive NS in childhood in Japan with the HLA-DR/DQ region [16], it is highly possible that some genetic factors are involved in the onset.

In our opinion, INS is a multifactorial disease in which immunological stimuli, i.e., viral infections trigger the production of substances that impair podocytes, resulting in dysfunction of the slit membrane or suppression of immunity by viral infection causing remission of INS.

We report a rare case in which spontaneous remission of NS occurred within a short period of 2 weeks after influenza B infection. This suggests that immunopathology is involved in the pathogenesis of INS, but there are some cases in which infection improves NS and others in which it relapse.

\section{Karger'=}


Case Reports in Nephrology and Dialysis
Case Rep Nephrol Dial 2021;11:103-109

\begin{tabular}{l|l}
\hline DOI: $10.1159 / 000515062$ & ( 2021 The Author(s). Published by S. Karger AG, Basel
\end{tabular} www.karger.com/cnd

Tamura et al.: A Case of Nephrotic Syndrome that Resolved with Influenza B Infection

\section{Acknowledgments}

We would like to thank the patient for participating in this study.

\section{Statement of Ethics}

All procedures performed in studies involving human participants were in accordance with the ethical standards of the Institutional Committee and the 1964 Declaration of Helsinki and its later amendments or comparable ethical standards (64th WMA General Assembly, Fortaleza, Brazil, October 2013). Written informed consent for examinations and to publish their cases including images was obtained from patients and/or their family members.

\section{Conflict of Interest Statement}

All authors declare that they have no conflict of interest relating to this case report.

\section{Funding Sources}

The authors received no financial support for the research, authorship, and/or publication of this article.

\section{Author Contributions}

T. Hiroshi cared for the patients and designed the project. N. Hiroko, F. Keishiro, H. Yuko, and K. Shohei collected clinical information. N. Hitoshi supervised the study. All authors have read and accepted the manuscript.

\section{References}

1 Shalhoub RJ. Pathogenesis of lipoid nephrosis: a disorder of T-cell function. Lancet. 1974 Sep;2(7880):55660 .

2 Lin CY, Hsu HC. Histopathological and immunological studies in spontaneous remission of nephrotic syndrome after intercurrent measles infection. Nephron. 1986;42(2):110-5.

3 Kimata T, Tsuji S, Kino J, Kitao T, Yamanouchi S, Kaneko K. Close association between proteinuria and regulatory T cells in patients with idiopathic nephrotic syndrome. Pediatr Nephrol. 2013 Apr;28(4):667-9.

4 Haruki A, Ishikawa E, Katayama K, Ito T, Hiramoto T, Fujimoto M, et al. Spontaneous remission of adultonset minimal change nephrotic syndrome associated with influenza B infection: a case report. BMC Nephrol. 2018 Jul;19(1):162.

5 Fujimura J, Ishimori S, Kamioka I, Okita S, Oyazato Y, Nishiyama A, et al. Clinical characteristics of relapsing idiopathic nephrotic syndrome associated with influenza virus infection or influenza virus vaccine in six pediatric patients. Japanese Journal of Pediatric Nephrology. 2017;30(1):35-40. 


\section{Case Reports in Nephrology and Dialysis}

Case Rep Nephrol Dial 2021;11:103-109

DOI: $10.1159 / 000515062$

(c) 2021 The Author(s). Published by S. Karger AG, Basel www.karger.com/cnd

Tamura et al.: A Case of Nephrotic Syndrome that Resolved with Influenza B Infection

6 Osanai H, Dohi K, Kato S, et al. Spontaneous remissions in three patients with minimal change nephrotic syndrome. J Nara Med Ass. 2002;41:404-11.

7 Sellin CI, Jégou JF, Renneson J, Druelle J, Wild TF, Marie JC, et al. Interplay between virus-specific effector response and Foxp3 regulatory T cells in measles virus immunopathogenesis. PLoS One. 2009;4(3):e4948.

8 Betts RJ, Prabhu N, Ho AW, Lew FC, Hutchinson PE, Rotzschke O, et al. Influenza A virus infection results in a robust, antigen-responsive, and widely disseminated Foxp3+ regulatory T cell response. J Virol. 2012 Mar;86(5):2817-25.

9 Karagiannidis C, Akdis M, Holopainen P, Woolley NJ, Hense G, Rückert B, et al. Glucocorticoids upregulate FOXP3 expression and regulatory T cells in asthma. J Allergy Clin Immunol. 2004 Dec;114(6):1425-33.

10 Kuzemko JA. Measles vaccination and the nephrotic syndrome. BMJ. 1972 Dec;4(5841):665-6.

11 Garin EH. Circulating mediators of proteinuria in idiopathic minimal lesion nephrotic syndrome. Pediatr Nephrotic. 2000;14:872-8. https://doi.org/10.1007/s004679900269.

12 Eddy AA, Symons JM. Nephrotic syndrome in childhood. Lancet. 2003 Aug;362(9384):629-39.

13 Kobayashi T, Ando Y, Umino T, Miyata Y, Muto S, Hironaka M, et al. Complete remission of minimal-change nephrotic syndrome induced by apheresis monotherapy. Clin Nephrol. 2006 Jun;65(6):423-6.

14 Lagrue G, Niaudet P, Guillot F, Lang P. Pregnancy and glomerulonephritis. Lancet. 1989 Oct;2(8670):1037.

15 Kikunaga K, Ishikura K, Terano C, Sato M, Komaki F, Hamasaki Y, et al.; Japanese Pediatric Survey Holding Information of NEphrotic syndrome (JP-SHINE) study of the Japanese Study Group of Renal Disease in Children. High incidence of idiopathic nephrotic syndrome in East Asian children: a nationwide survey in Japan (JP-SHINE study). Clin Exp Nephrol. 2017 Aug;21(4):651-7.

16 Jia X, Horinouchi T, Hitomi Y, Shono A, Khor SS, Omae Y, et al.; Research Consortium on Genetics of Childhood Idiopathic Nephrotic Syndrome in Japan. Strong association of HLA-DR/DQ locus with childhood steroid-sensitive nephrotic syndrome in the Japanese population. J Am Soc Nephrol. 2018 Aug;29(8):218999.

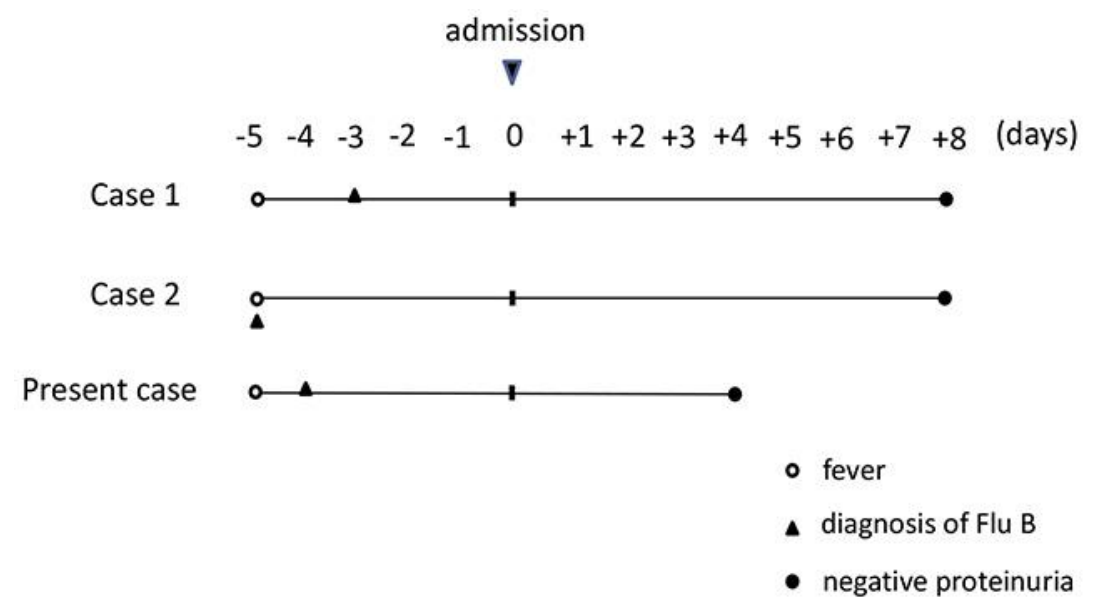

Fig. 1. Clinical course of NS patients with influenza B infection. The clinical course of these three cases was similar. All cases lacked data regarding proteinuria on the day of the influenza B infection diagnosis. 
Case Reports in Nephrology and Dialysis
Case Rep Nephrol Dial 2021;11:103-109

(c) 2021 The Author(s). Published by S. Karger AG, Basel (c) 2021 The Author(s).
www.karger.com/cnd

Tamura et al.: A Case of Nephrotic Syndrome that Resolved with Influenza B Infection

Table 1. Summary of NS patients with influenza B infection

\begin{tabular}{llll}
\hline & Case 1 & Case 2 & Present case \\
\hline Age/sex & 50 years/female & 5 years/male & 18 years/female \\
Pathology & MCD & Not examined & MCD \\
Medication for NS & - & - & - \\
Time from fever to admission (days) & 5 & 5 & 5 \\
Time from diagnosis of Flu B to admission (days) & 3 & 5 & 4 \\
Alb (g/dL) on admission & 2 & 1 & 0.9 \\
u-pro/cre (g/g) on admission & 20.88 & 26 & 8.73 \\
Time from hospitalization to negative proteinuria (days) & 8 & 3 & 4 \\
Reference & 4 & 3 & present case \\
\hline
\end{tabular}

